Artículo recibido el 12 de noviembre de 2020. Aceptado para publicación el 18 de diciembre de 2020

\title{
Indigenous Knowledge and Navigating the Rising Tides of Climate Change and Other Existential Threats
}

\section{Conocimiento Indígena y la navegación de crecientes mareas del cambio Climático y otros desafíos existenciales.}

Jerry Lipka ${ }^{1}$

\begin{abstract}
Existential threats to Indigenous People's lands, cultures, and languages are exacerbated and intensified by climate change and its effects, particularly to those groups deeply connected to natural systems. Through five case vignettes situated in Alaska, Yap State, and the Republic of the Marshall Islands, this paper describes adaptive responses at the intersection of Indigenous Knowledge (IK) and climate change. Though their locations, history, and customs vary, they share an underlying similarity in the urgency expressed for their Traditional Ecological Knowledge to be part of a response that leads to sustainability. Navigating these rising and turbulent waters requires new ways of thinking, political will, governmental leadership, and values commensurate with harmonious living. To write this paper required a significant change in a paradigm that guided my work in ethnomathematics from the school context to the larger social-cultural-ecological systems.

Key Words: Indigenous Knowledge, Traditional Ecological Knowledge, Climate Change, Ethnography, Ethnomathematics, Case Vignettes, Yupiaq, Federated States of Micronesia, and the Republic of the Marshall Islands.
\end{abstract}

\section{Resumen}

Las amenazas a la existencia de tierras, culturas y lenguajes de los pueblos indígenas se ven exacerbadas e intensificadas por el cambio climático y sus efectos, en particular para los grupos profundamente conectados a los sistemas naturales. A través de cinco viñetas de casos situados en Alaska, el estado de Yap y la República de las Islas Marshall, este texto describe las respuestas adaptativas en la intersección del conocimiento indígena y el cambio climático. Aunque sus ubicaciones, historia y costumbres varían, comparten una similitud subyacente en la urgencia expresada de que su Conocimiento Ecológico Tradicional sea parte de la respuesta que lleve a la sostenibilidad. Navegar por estas turbulentas y crecientes mareas requiere nuevas formas de pensamiento, voluntad política, liderazgo gubernamental y valores acordes con un vivir armonioso. Escribir este artículo requirió un cambio significativo en un paradigma que guió mi trabajo en Etnomatemáticas, desde el contexto escolar hacia sistemas socioculturales-ecológicos más amplios.

Palabras Clave: Conocimiento Indígena, Conocimiento Ecológico Tradicional, Cambio Climático, Etnografía, Etnomatemáticas, Viñetas de Caso, Yupiaq, Estados Federados de Micronesia, y la Republica de las Islas Marshall.

\footnotetext{
${ }^{1}$ Emeritus Professor at the School of Education. University of Alaska Fairbanks. Email: jmlipka@alaska.edu
} 


\section{INTRODUCTION}

\subsection{A Personal Introduction-The Challenge}

Exploring multifaceted complex systems through case vignettes as a way to frame existential threats to Indigenous languages and cultures represents a radical departure from the ethnographic approach that I employed at the nexus of cultural conflicts in the school. The vignettes provide a way to begin to understand a social-cultural-ecological systems approach. A systems approach connects macroeconomics, microeconomics, governmental policies, population, consumption patterns, ways of living, worldviews, and epistemologies. This approach connects global and local behavior and, in this paper, how actions and behaviors rippling through these systems disproportionately impact Indigenous People, particularly those closely connected to their lands. The case vignettes approach illuminates initial thoughts on how to combat these existential threats. Such a perspective includes all of us and the disconnections between our actions and their impacts affecting the people we are collaborating with. This was a painful paper to write. Although it is inadequate, the paper begins a dialogue to address these difficult topics. I thank Monica Mesquita for challenging me to break the mold of my thinking.

Existential threats to Indigenous People's lands, cultures and languages are exacerbated and intensified by climate change and its effects, particularly to Indigenous cultures deeply connected to natural systems. Through case vignettes, this paper describes adaptive responses at the intersection of Indigenous Knowledge (IK) and climate change. By immersing myself through intensive reading about some of the human actions that are leading to climate change and how the results of those actions are affecting Indigenous People across North and South America (tundra and Amazonian jungles) and vast archipelagoes of Micronesia, the sheer cruelty of dehumanizing acts forced upon Indigenous People deeply affected me. Yet these struggles have also ignited resistance, resilience, and adaptiveness, and led to the formation of new alliances within and across Indigenous communities and across institutional boundaries with allies from universities, governmental agencies, and donor groups (among others). The case vignettes described in this paper address these indignities, complexities, resilience, and adaptive responses that indicate possible paths forward.

Indigenous People, because of their intimate connection to and knowledge of the local ecologies, lands, waters, and ice they live on or near, are well positioned to contribute to solutions. Navigating these rising and turbulent waters requires new ways of thinking, political will and governmental leadership, and values commensurate with harmonious living. The Yupiaq Elders 
and the Federated States of Micronesia (FSM) ${ }^{2}$ knowledge holders that we have worked with embodied these values in their actions and words.

All of us are affected by climate change, but Indigenous People disproportionately experience the related consequences because of their reliance on and relationship with the natural environment. Changes in the landscape and seascape affect weather and identifiable patterns used for traveling. Rising waters and land erosion are affecting Native villages in coastal western Alaska and the low-lying atolls of Micronesia. Physical dislocation, high costs of fuel, increased reliance on the cash economy, and limited economic opportunity put increasing pressure on traditional ways of life, threatening Indigenous cultural and ecological knowledge. In exploring the opportunities and challenges raised by existential threats, a case vignette approach shows multiple responses possible at the local level. The vignettes highlight 1) collaborations, 2) cultural regeneration, 3) Traditional Ecological Knowledge (TEK), 4) economic opportunities, and 5) systemic linkages as a metric for sustained change. The profile of each case highlights different factors, contexts, and outcomes. Analysis of the vignettes helps organize potential change strategies.

This paper reflects a significant change in a paradigm that guided my work over four decades. The paradigm revolved around the cultural psychology theory and the earlier cultural historical theory (Cole, 1998; Cole \& Engeström, 1993) and how it was applied to micro-aggressions occurring at the intersection of curriculum, teaching, and learning between Indigenous students and teachers in Western-oriented classrooms. I have expanded upon this theory, as it needs a wider view - a social-cultural-ecological perspective that includes a systems approach linking ecospheres and ethnospheres, and by its complexity requires collaborative relationships with Indigenous nongovernmental and Tribal organizations and their allies (see Cochran et al., 2013; Cochran is a member of the Alaska Native Science Commission-ANSC). This perspective increases the range of interventions from micro to macro, to learning that can occur in school and out of school with Elders and scientists and mathematicians/educators; it seeks to solve problems and breaks the mold by altering human-environment interactions.

\footnotetext{
${ }^{2}$ I started working in FSM in 2009 when Sandy Dawson invited me to join the advisory board of project MACIMISE (Mathematics and Culture in Micronesia: Integrating Societal Experiences). Subsequently, I received a National Science Foundation award from 2013 to 2018 which included Alaska and FSM.
} 


\section{BACKGROUND: BIOSPHERE AND ETHNOSPHERE}

The economics of large advanced technological and industrial societies (generally) disregard the adage "there is no such thing as a free lunch." When large industrialized societies do not take responsibility for the impacts of their acts, that is, when there is insufficient regulation or lack of mutual agreement, the marginal gains they enjoy for "taking one more fish" can lead to the “tragedy of the commons" (Hardin, 1968). ${ }^{3}$ Earth's commons, Mother Earth's bounties, have suffered degraded ecosystems, from exploitation of fisheries to careless extractive mining and oil and gas exploration. The Ecological Footprint (Wackernagel \& Beyers, 2019) is a metric accounting of the earth's resilience and carrying capacity versus the demands placed on it per person or per country per year. Humanity exceeds the earth's sustainability by 1.6 earths (https://www.footprintnetwork.org/our-work/ecological-footprint/). This strain on the earth's capacity is predicted to grow exponentially over the next few decades. The strain factors include overpopulation, the concomitant problem of waste, the ill-effects of burning fossil fuels, overconsumption, the influx of alien species, and the loss of biodiversity and cultural diversity (see Chapin, 2020, for a comprehensive overview of this topic).

\subsection{Indigenous Knowledge in Navigating Climate Change}

The loss of Indigenous Knowledge has increasingly been cited as a loss for all humanity. The Intergovernmental Science Policy-Platform on Biodiversity and Ecosystem Services (IPBES) "is the first global-level assessment to systematically consider evidence about the contributions of Indigenous and local knowledge and practices" (IPBES, 2019, p. 3). The IPBES summary for policymakers states, "indigenous peoples and local communities have often managed their landscapes and seascapes in ways that were adjusted to local conditions over generations. These management methods often remain compatible with, or actively support, biodiversity conservation by 'accompanying' natural processes" (IPBES, p. 31). Indigenous People make up a small percent of the world's population, yet they occupy approximately $25 \%$ of Earth's land areas. These areas include most of the world's diverse species (Veit \& Reytar, 2017) and account for most of the world's linguistic and cultural diversity (Davis, 2003).

\footnotetext{
${ }^{3}$ I do not agree with Hardin's elitist view and solutions based on inaccurate anecdotes, but I do agree with his analysis on how profits gained from taking one more (fish or adding more animals to a pasture) can create an inverse correlation between profits and ecological sustainability. The end game is tragedy. Aristotle is reputed to have said this approximately 2,300 years ago.
} 
The case vignettes were chosen because they represent the qualities mentioned earlier of efforts that break the mold and hold promise for establishing transformative relationships. Each vignette, with its unique circumstances and contexts, intersects the social-cultural-ecological system at a different point. Together, they provide insights into a regenerative social-cultural ecology. Three case vignettes are from Alaska, one is from the Federated States of Micronesia (FSM), and one is from the Republic of the Marshall Islands (RMI). The Pacific centric map in Figure 1 highlights the atolls and islands of FSM and RMI (not drawn to scale) and Alaska.

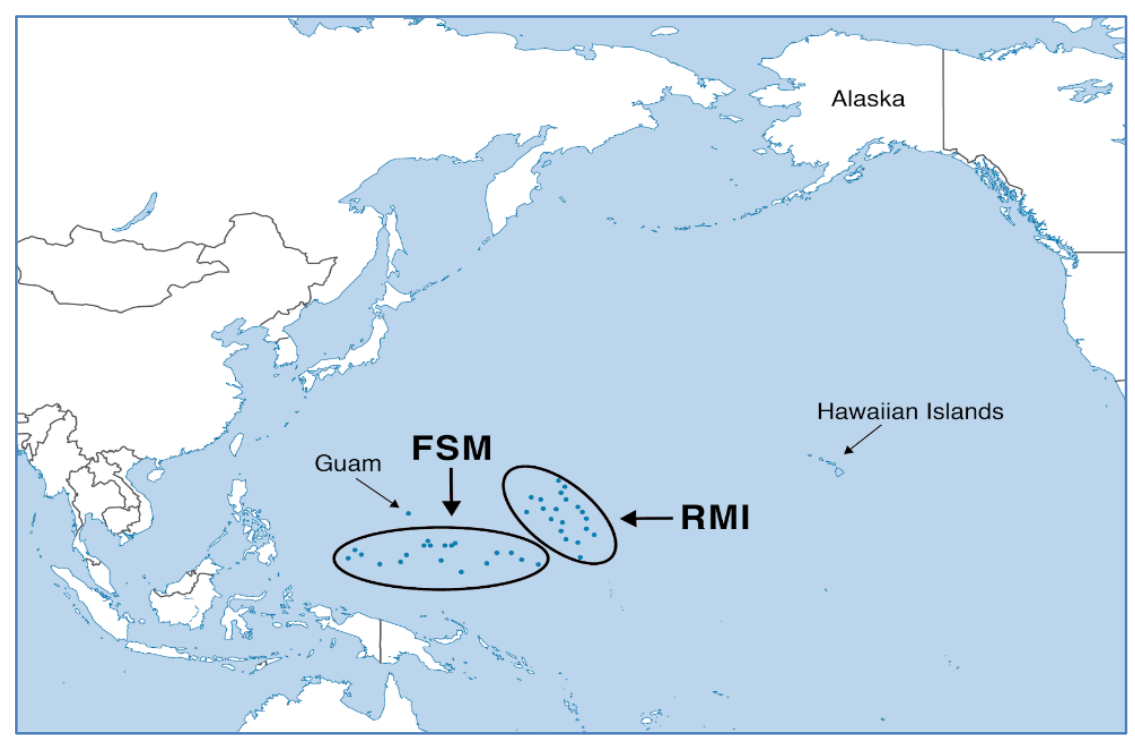

Figure 1: Pacific centric view Source: Drawing by Keely Colby

\section{CASE VIGNETTES}

\subsection{Alaska Cases and a Brief History: U.S. Law and the Alaska Native Claims Settlement Act (ANCSA)}

The U.S. Constitution established a government-to-government relationship with American Indian tribes, an asymmetrical trust relationship which states that the federal government holds the final say in American Indian affairs. The states lack the authority to settle Aboriginal land claims. Yet, executive and state policies, among other actions, were used to dislocate, take land away from, and brutally treat the Aboriginal People of the U.S. The discovery in 1967 of massive oil reserves in Prudhoe Bay, Alaska, was the catalyst to settle the state's Aboriginal land claims to enable the flow of oil. In 1971, the Alaska Native Claims Settlement Act (ANCSA) resolved land ownership between Alaska Native people, the state, and the federal government, 
establishing 12 Regional Native Corporations, for-profit village corporations, and nonprofit corporations. ANCSA created a capitalistic model which injected a possible divide between forprofit and nonprofit Native organizations.

\subsection{Inspiration, Resistance and Resilience}

All of us can draw strength and inspiration from a small group of Inupiaq hunters and their allies who thwarted the Atomic Energy Commission (AEC), which planned to set off nuclear bombs near Point Hope, Alaska, to develop a deep-water port (O’Neill, 1994). The cold war tensions between the USSR and the U.S. led the Atomic Energy Commission to send scientists to northwest Alaska to explain the development of the port. Though the project was supported by the President of the University of Alaska, a group of scientists from the university did not support the plan. They provided technical assistance and moral support to the small group of Inupiaq hunters who opposed the AEC. The U.S. government did not expect resistance from this surprisingly informed group of hunters. One of the hunters had served in the armed forces during World War II and was keenly aware of the devastation of nuclear bombs. His unit had been detailed with "cleaning up" nuclear bomb aftermath (see Firecracker Boys by Dan O'Neill, 1994, for more details). This historical incident at Point Hope raises a theme that appears throughout this paper, how resistance to oppressive incursions into Indigenous land and threats to Indigenous lifeways became a catalyst to form unlikely collaborative partnerships. Resistance is occurring in the Bristol Bay region of Alaska, home of the Yupiaq people, and the world's richest sockeye salmon fishery and the proposed location of a business venture, Pebble Mine, which would be one of the largest gold, copper, and molybdenum mines in the world. For over 20 years, Yupiaq organizations have fought against the proposed development of the Pebble Mine. Unemployment is high throughout the region, and the mine would offer employment to some local Yupiaq people and communities. Yet, the pristine waters of Bristol Bay provide bodily and spiritual sustenance to the Yupiaq. Dora Andrew-Ihrke (long-term colleague) and her uncle, Bobby Andrew ${ }^{4}$ before her, have been fighting this mine, and now her son continues in this resistance. Another case of resistance in Alaska is that of the Gwich'in People of Arctic

\footnotetext{
${ }^{4}$ Bobby Andrew founded Nunamta Aulukestai, which means "Caretakers of the Land." The group opposed Pebble Mine, and Bobby travelled to London to meet Anglo Americans CEO Cynthia Carroll and Board Chairman Sir John Parker to express the opposition of local people. Bobby was successful, as the Anglo American PLC withdrew from this project. (See the editorial by Bobby Andrew and George Wilson Jr., Fighting the Alaskan Wilderness Mine, The Guardian, Friday October 29, 2010). Today this struggle continues.
} 
Village and Venetie, who continue their 30-year struggle to resist oil development in the Arctic National Wildlife Refuge (ANWR) because of their sacred ties to the land and caribou. Some Indigenous for-profit organizations on the Alaska North Slope established by ANCSA support oil development. There are different levels of support and opposition across Alaska Native communities as more large-scale mining developments affect swaths of Alaska, highlighting a fundamental dilemma between the protection of subsistence resources and traditional practices of hunting, fishing, and gathering, and opportunities presented in a cash-based economy.

\subsection{Case Vignette: The Conundrum of Schooling and Imagining the Path Not Taken- Traditional Ecological Knowledge and Community Organizations}

\subsubsection{The Desire for Western Schooling: Traveling Downstream}

In the early 1970s, only seven certified Alaska Native teachers were employed throughout the state of Alaska. Except for the bilingual aides and instructors, the curriculum, teachers, principals, and superintendents were mostly from elsewhere (Kawagley, 2006; Lipka with Mohatt \& the Ciulistet Group, 1998). Keenly aware of the acculturation process occurring in rural Alaska, the organization Yupiktak Bista (1974) wrote a report entitled, Does one way of life have to die so that another can live? They stressed the desire of local Yupiaq communities for schooling while painfully recognizing the alienating effects of schooling on students' identity. In 1974 the University of Alaska Fairbanks (UAF) created a teacher education program for rural and Indigenous students. One key objective of this program was to have schools reflect a community's culture.

I arrived in Alaska in 1981 to join this teacher education program in the Bristol Bay region. One of my students, William Gumlickpuk, who was the mayor, a commercial salmon fisher, and a teacher aide in the village of New Stuyahok, invited me to go on a hunting trip. We traveled by motorized skiff from New Stuyahok up the Nushagak River and further upstream on the Mulchatna River. These rivers are part of the rich Bristol Bay salmon fishery. Mile after mile, the country and the river were pristine. The earth's bounty was all around us. Some hours later, we met up with other hunting parties from New Stuyahok and stopped for tea and pilot bread at a sandy gravel bar at the confluence of the Stuyahok and Mulchatna rivers. Usually at gatherings, stories are told. I recall Chief Ivan Blunka telling how he decided decades before to move the old 
village to New Stuyahok (in Yup'ik' Cetuyaraq, which literally means "to go with the river current") ${ }^{6}$. We returned to the boats and traveled to the original village site of Stuyahok, where we stopped once again and briefly got out. Chief Blunka mentioned that he had wanted the youth to have an education, but that the old village site was too far upstream for the Bureau of Indian Affairs (BIA) to establish a school. (It was the BIA that provided education to Indigenous Alaskans while Alaska was still a U.S. territory, until 1959.) Chief Blunka moved the village to the new location of New Stuyahok sometime in the 1940s, and in the early 1950s the BIA established a school. William Gumlickpuk was one of the youngsters in the 1950s to experience formal Western schooling.

Unfortunately, I do not believe that Elders such as Chief Ivan Blunka-who made large sacrifices to have a school- ever expected that the school would accelerate the process of culture and language loss. Nor would he ever have imagined what is happening today: that just a few miles upstream of the old village site helicopters would be flying around and landing at an international mining company's camp site, preparing to develop a mega mine near ancestral lands, ${ }^{7}$ the headwaters of this rich salmon fishery, and unspoiled wilderness. Nor did I foresee the extent of all these changes.

\subsubsection{The Path Not Taken with the Long-term Practitioner Scholar Group}

A key outcome of working in the teacher education program in Bristol Bay was the formation of a long-term collaborative group of newly minted teachers, Yupiaq Elders from this and other regions, and academic consultants. The formation of the group developed out of mutual respect and common goals regarding cultural continuity. Most Elders desired that their youth become thinkers, problem-solvers, and bilingual speakers. The immediate effect of working with Elders was that the Yupiaq teachers, teachers-to-be, and academic consultants kept marveling at the Elders' knowledge. Our informal, committed group was familial. For example, some Elders following tradition named my children after their recently deceased relatives, creating fictive kinship ties. As trust developed in the group, Elders and Yupiaq teachers began sharing humiliating experiences. Frederick George, an Elder and one of the most intelligent and creative

\footnotetext{
${ }^{5}$ Yup'ik and Yupiaq are often used interchangeably by fluent speakers. Yupiaq refers to the people, meaning the real people, while Yup'ik refers to the language.

6 Translation provided by Dora Andrew-Ihrke

${ }^{7}$ The final decision to allow the mine to develop beyond the exploration stage has not been made as of this writing, and the mine is highly contested. Approximately $70 \%$ of local people are against it.
} 
persons I have ever met, stated how he had been treated by "outsiders" as if he was a "know nothing." An administrator of a local school district, which financially supported the group's early meetings, said (paraphrasing), "you [teacher and Elder group] won't find anything because they do not have any culture." I was incredibly fortunate to work with such a dedicated, hardworking, and gifted group of Yupiaq Elders and former Yupiaq students who graduated from the teacher education program, particularly Evelyn Yanez, Dora Andrew-Ihrke, and Sassa Peterson. All were a critical cohesive part of our work for the next 35 years.

Because I have written extensively on the group's long-term collaborative work in ethnomathematics and pedagogy (see Lipka, with Mohatt \& the Ciulistet Group, 1998; Lipka et al., 2019; Lipka, 1991; \& Lipka, 1990), I will not describe it here. Instead, I will focus on the path not taken by imagining how we could have recentered our work with community and Tribal organizations as a counterforce to the assimilationist practices of schooling and, more positively, created new community spaces to deliberately involve youngsters in their culture's rich traditions. Instead of expending so much energy within the chaos of these schools - disruptions that resulted from rapid turnover of teachers and superintendents, and changes in curriculumwe could have changed the group's orientation by working more directly with tribal and community organizations while continuing to work with the school. Our group could have sought new spaces with the tribal organizations and with a variety of regional, state, federal, and university programs where they intersect Traditional Ecological Knowledge (TEK). These speculations stem from work we did with scientists and Elders that most likely would have been embraced by Tribal entities.

\subsubsection{Changing Paradigms and Reimagining}

The Yupiaq teachers and Elders group was an enduring, powerful, and creative force. At the peak of our efforts, 70 Elders were involved, and a 10-member core group worked for the project's duration or until their passing. ${ }^{8}$ The concept of "cultural camps" as a way to reinforce and support TEK has long been proposed (Kawagley, 2006; Chapin, Knapp, Brinkmann, Bronen, \& Cochran, 2016; Barajas-López \& Bang, 2018). In Alaska, fish camps occur each spring/summer as villagers move downriver closer to bays. Fish camps are a part of Indigenous cultural practices, a time when fish are caught, cleaned, dried, smoked, and usually shared amongst family groups. Modeled on fish camps, cultural camps could be authentic sites for

\footnotetext{
${ }^{8}$ Working with the Elders was a privilege and a pleasure. We were true colleagues.
} 
cultural transmission through a variety of activities led by Elders to help retain and reinforce local TEK. Groups such as ours - Yupiaq Elders, teachers, and university academics_-could have worked with Tribal entities supporting local cultural activities in the community.

Knowledge learned in the cultural camp could then have been bridged with schools. In actuality, Elders who were part of the core group did, at some community meetings, create school-based curriculum material with Yupiaq and nonYupiaq teachers, insider and outsider academics, and ethnomathematicians. These were powerful moments that, in retrospect, could have and should have occurred more frequently (see Lipka with Mohatt \& the Ciulistet Group, 1998).

\subsubsection{Turning Points}

The core group of Elders would have been keenly interested in working on issues pertaining to observed changes to the environment. Our group would have had ample opportunities to work with scientists studying changes in climate, land ecology, and the salmon watersheds. State and federal agencies charged with subsistence use of the lands would have provided additional opportunities. How do I know? I know because in an early stage of our group we did work with scientists from the university; we did work with state and federal agencies concerning reestablishing a caribou herd. We did work directly with local and regional Native corporations regarding land use and involving youth from outlying villages, and we coordinated with local school districts and developed the Bristol Bay Curriculum Project (Lipka \& Willer, 1985) that supported these efforts.

In 1995 I submitted my first federally sponsored research proposal in ethnomathematics and ethnoscience. The research sponsors asked us to drop ethnoscience. Ironically, this laid the foundation for my/our work in ethnomathematics within a school setting. This work going forward was entitled Math in a Cultural Context (https://www.uaf.edu/mcc/).

\subsubsection{Star Navigation as a Cultural Camp Experience}

Frederick George was one of the few remaining star navigators when I met him, and we worked together for approximately 7 years before we could write the Star Navigation curriculum module for the Math in a Cultural Context (MCC) program which was sponsored by the National Science Foundation (NSF). In part, it took 7 years because the concepts behind Frederick's words and bodily gestures were difficult to comprehend by both insiders and outsiders, including esteemed Elders, mathematicians, and math educators. See Engblom-Bradley (2006) for a description of Frederick's method, and see Adams, Kagle, \& George (2007) for a classroom 
module and a Star Map 9 as perceived by Yupiaq Elders.

(https://uaf.edu/mce/files/posters/MCC_Sky_Map_CC.pdf).

To star navigate, you need to know such things as how to predict weather and how to build emergency shelters; you need to memorize place names and observe subtle environmental clues from seasonal indicators such as snow waves and "paths" created by frozen grass covered by snow. You also need knowledge of traditional methods of measuring angles, accounting for time and distance, stories that reinforce routes, and how wind-bent trees provide direction. Frederick clearly showed us how Kaviaraat (the Fox) contains Agyarrluk (the North Star) which is at the center of his system; the two constellations that rotate around the North Star are Tunturyuk (the Caribou) which refers to the Big Dipper and Oengartarak (the Nose with Two Nostrils) which refers to Cassiopeia providing critical information about time, location, and direction. Figure 2 is a computer enhanced version of how Frederick George and other Yupiaq Elders drew their view of Cassiopeia, the North Star, and the Big Dipper.

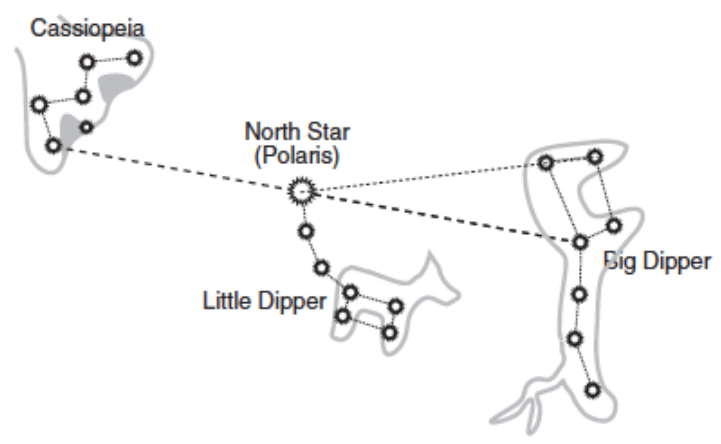

Figure 2: Yupiaq constellations used in star navigation

Source: Drawning by Putt Clark

Parenthetically, years later the practitioner/scholar group realized the importance of qukaq (the center) as an underlying concept that cuts across most everyday activities. It functions as a place to measure from, to begin projects, and to orient frames of reference, and it was used by Frederick while star navigating (Lipka, Adams, Wong, Koester, \& Francois, 2019). Similarly, if we (members of the group) had apprenticed with Frederick George, then other subtle and important cultural and linguistic knowledge associated with the environment would have arisen. For example, according to Jacobson (1984) and Tamura (2017) the demonstrative system in the Yup'ik language (like the English this/that) and adverbs (like the English here/there) has a total

\footnotetext{
${ }^{9}$ As far as I know, this is the only extant Yupiaq Star Map. Frederick George, Sam Ivan, Henry Alakayak, and I met in Anchorage's planetarium where we could "control" the night sky making it easier to see the Yupiaq constellations and their positions.
} 
of 30 sets, while English has two sets. Some examples of the Yup'ik system include closeness to the speaker, up/down, in/out, moving/stationary, and visible/obscured, and some demonstratives are coordinated with glances. This complex system assists in establishing frames of reference. Learning these cultural nuances and how to star navigate can only be achieved under the night sky through apprenticeship. The ability to process visual sensory inputs, from stars and landmarks to body sensations experienced when crossing snow waves, and interpret them in realtime, can only occur under these epistemic conditions.

\subsubsection{Collaborating with Tribal Organizations (to strengthen traditional culture knowledge)}

The MCC program held intensive two-week-long Summer Math Institutes at the University of Alaska Fairbanks (UAF) with Elders and Yupiaq teachers/consultants. We could have shifted these meetings to villages as a way to support TEK and cultural camps. Years ago, our group held a meeting in the Kuskokwim River community of Akiachak, Alaska, with two scientists from the Jet Propulsion Laboratory. Akiachak is where Frederick George and many knowledgeable Elders lived. The well-attended meeting was held at the school and included our group from Bristol Bay, Elders from Akiachak and other villages, and teachers. After introductions, Joshua Phillip, a well-respected leader, invited everyone present to go outside where the scientists were challenged to forecast the weather and explain what observations they based their forecast on. Neither scientist could do so based on environmental observations, but the Elders present could. The Elders accomplished their goal of creating a respectful relationship, demonstrating that each group brings knowledge to the table. Given the wealth of local knowledge and the potential support from leaders in the Yupiit ${ }^{10}$ sovereignty movement and the local school board, it may well have been possible to further establish these novel spaces. Shifting the emphasis of our work from the school to community organizations could have been a strategy more in line with a regenerative social-cultural ecology. ${ }^{11}$

\footnotetext{
${ }^{10}$ Mike Williams is the chief of the Yupiit Nation, a group of federally recognized tribes centered in Akiachak, Akiak, and Tulusak in the Kuskokwim area of Alaska. The word Yupiit is plural, Yupiaq is dual, and Yup'ik is singular.

${ }^{11}$ In fairness to our previous efforts, we chose to work within the school context, wanting to meet the requirements of Western schooling in a way that was supported both by the Elders and the Yupiaq teachers. This was a good model.
} 
Lipka, J. (2020). Indigenous Knowledge and Navigating the Rising Tides of Climate Change and Other Existential Threats. Revista Latinoamericana de Etnomatemática, 13(3), 29-61. DOI: 10.22267/relatem.20133.66

\subsection{Case vignette: innovation in the alaska gateway school district-breaks the mold}

\subsubsection{Background}

The Alaska Gateway School District (AGSD) is on the road system in Alaska's eastern Interior near the Canadian border. The AGSD consists of 7 schools and approximately 430 students. The district's largest population center is Tok, with a population almost $80 \%$ Caucasian, while the rest of the district is mostly Athabaskan.

This school district tends to be politically conservative. Unlike many Alaska school districts, the AGSD has had stable and innovative leadership. I worked with Dora Andrew-Ihrke in this district for many years providing support for the MCC curriculum, including teacher inservice workshops, classroom observations and co-teaching, and some discussion with Indigenous community members and teachers-in-training. A few years ago, the AGSD formally adopted the MCC supplemental math curriculum based on Yupiaq Elders' Knowledge. An enthusiastic future teacher from Tetlin village joined our Elder/teacher group for a few years.

\subsubsection{A School District's Stewardship_Cleaner Energy, Lowering Carbon Footprint, Healthy}

\section{Food, and Forest Fire Burn Strategies}

This vignette centers on the AGSD's interest in local energy production and consumption, carbon emissions, healthy food production, and stewardship of the surrounding taiga forest. The vignette is presented as narrative, spoken by Scott MacManus, the school district superintendent, about fostering transformational innovations.

To break dependence on dirty fuels, Scott developed a set of atypical relationships that cross school boundaries and extend to village governments, the regional nonprofit Native organization (Tanana Chiefs Conference/TCC), the local energy company, the community of Tok, and the Alaska Energy Authority. He described his efforts to me as follows:

I first started this project because Tok has a problem with wildfires. I have lived in Tok for 22 years. During this time, my family and I had to mobilize and ready ourselves to evacuate on a moment's notice on four separate occasions. Two times we did evacuate. Wildfire is an issue. We have a super thick taiga forest (white and black spruce with lichen and moss). The forest contains a high amount of biomass. [In recent years, Alaska's Interior temperatures have grown warmer, and fires have become more frequent and intense.] Fire will race through the forest at 30 miles an hour. This creates a dangerous situation.

I would notice local guys burn massive piles of spruce and manage these fires. This method of fire suppression created dense smoke. One night I met with this guy Jeff. He suggested the 
idea of using the wasted biomass to heat the school. The Alaska Energy Authority (AEA) came to our community to talk about innovative energy grants. They held a town hall meeting in Tok. Jeff and I asked AEA if we could present at this community meeting. They were not encouraging. We set up our presentation anyway. We were prepared for a 10minute presentation. The presentation became the meeting. After the meeting, one member of AEA encouraged us to apply for a grant. We had already run some feasibility projects. We applied and received approximately 3.5 million dollars. We put together a hydronic (heated hot water running through pipes and transferring heat to the school) heating system. It heats water to 180 degrees, and it can heat the Tok school. When you crunch the numbers, the project pays for itself. However, I wanted to include steam to power electricity.

The local utility company rejected Scott's plan for powering electricity. Scott realized that if he added a steam boiler to the project he could heat and provide electricity to the school. He was able to negotiate a small grant to pay for the steam boiler. Through lobbying the state legislature, he was able to get a sufficient grant to develop a steam system. With out-of-the-box thinking, Scott was able to locate a $60 \mathrm{kw}$ Elliot turbine generator and have it repaired and shipped across the country to Tok, where it became fully operational in 2014 and has been used ever since.

We are now working on a cooperative venture with the Tribal Councils in Mentasta and Northway. The new projects include: a) biomass in Mentasta, and b) a biomass energy and greenhouse system for Northway. The idea for Tetlin did not work; it was a cord wood system. You have to cut the wood and use it like a wood stove; it is labor intensive and hard to control the system... it was not a chip bed system.

We had too much heat. The system needs to be running cool enough to work properly and we put in the greenhouse to offset the heat load. The greenhouse is 33 feet by 100 feet long. It is just like a standard commercial greenhouse. Engineers designed it.

The students are now involved in Arctic Agriculture, and we treat it as a commercial endeavor and offset the costs. This has improved the quality of the food that we serve to students. Students work in the greenhouse year-round. We have classes in Arctic Agriculture, and articulated biology classes with the university. As we gain more efficiency, we will produce 10,000 pounds of produce a year-lettuce, broccoli, carrots, cucumbers, cherry tomatoes. The kids love to work in the greenhouses. The greenhouse related classes fill right up.

Fire control: We have a Wildfire Community Prevention Plan. It identifies biomass on state land. We cut trees and brush strategically, allowing staging for firefighters. These cuts supply wood/fuel for the power plant. It is a coordinated effort.

Experienced cut crews [many from local villages] train novice firefighters on how to make cuts that make out-of-control fires less likely. They work all summer as a team. They get all the certifications that they need to fight fires. Young men and women come and get the training. The management of the crews is being filled from within this group. It is the only project like this in the state.

The project's collaborators include TCC fire crews, the Alaska State Division of Forestry in Tok, the Alaska Energy Authority, and the University of Alaska Fairbanks. This case is not an 
example that includes Indigenous Knowledge; however, the innovative thinking and cooperation of the community, Tribal groups, and others involved help educate students in energy use and land stewardship, and has helped to reduce energy costs in Native villages and create employment opportunities. In addition, this project is poised to grow. Projects like this can have a ripple effect, as other districts may well want to pursue such options particularly when costs come down. The opportunity for involving Indigenous Knowledge is possible, as studies by Chapin, Trainor, Huntington, et al. (2008) show that some Interior Tribal groups used preventive fire burns to suppress wildfires and to encourage the growth of plants that the village relied on.

\subsection{Case Vignette: Community Partnership for Self-Reliance}

\subsubsection{Background}

The Yupiaq village of Igiugig (Igyararmiut-like a throat that swallows water), population 69, lies where the largest freshwater lake in Alaska flows into the Kvichak River. Igiugig is in the Bristol Bay area, home of the world's largest red salmon fishery: 57 million red salmon (caught and escapement), which roughly translates to 219 million pounds. (The rest of the world contributes 162 million pounds, based on 2018 data reported by the Bristol Bay Regional Seafood Development Association.) Over 4 million salmon pass by the village of Igiugig. Like the old village of Stuyahok, Igiugig is near the proposed open-pit Pebble Mine. As of this writing no decision for permitting this industrial plan has been made by the U.S. Army Corps of Engineers. The consequences of a decision that permits Pebble Mine to operate will affect the entire region ${ }^{12}$.

\subsubsection{An Epiphany}

F. Stuart Chapin III, known as Terry, is a world-class ecologist, a member of the National Academy of Science, and the recipient of numerous awards. Terry's epiphany (Chapin, 2020, p. 106) as an ecologist came when he invited Larry Merculieff, an Alaska Native leader and ANSC member, to speak at the University of Alaska Fairbanks (UAF) on sustainability from an Indigenous perspective and heard his invited speaker's words: "It's time you researchers stop exploiting native communities and do something useful for a change ... Communities should decide what needs to be researched and who should be invited to do this work. The exploitative

\footnotetext{
${ }^{12}$ Right before this paper went to press, the Army Corps of Engineers denied a permit for this massive mining project. This decision greatly reduces the chance that this project will go forward.
} 
relationship between researchers and communities has got to stop" (Chapin, 2020, p. 106). Terry worked with Larry Merculieff and Patricia Cochran (ANSC) for over two years to establish a plan that would meet the criteria of equitable and respectful relationships with Alaska Native communities. They developed a transdisciplinary and community approach to address climate change and ecological sustainability, both of which are fundamentally complex and multidimensional. Their approach, described in Chapin et al. (2016), is entitled Community Partnership for Self-Reliance (CPS). The partnership includes the Alaska Native Science Commission (an Alaska Native Tribal NGO), faculty and graduate students at UAF, and Native leaders. Terry obtained a commitment from different departments and faculty at UAF that included flexibility from faculty groups with technical expertise that would be called on depending on the type of assistance that villages required.

The CPS plan asked different communities to apply for the technical assistance they required in the broad area of social ecology (such as high costs of fuel, flooding due to climate change, and other barriers to self-reliance). Communities applied to be part of the project, and the CPS team selected four communities, one of which was the village of Igiugig, the focus of this vignette. At meetings held in the village, the community identified the high cost of energy, pollution, and cultural revitalization as areas in which they needed assistance. The community, under the capable leadership of AlexAnna and Christina Salmon, could resolve other issues. Because the community had looked for alternatives to fossil fuels and had already experimented with some alternative energy systems, it needed more advanced technical assistance in the integration of renewable energy into diesel power systems. Terry invited the participation of the Alaska Center for Energy and Power (ACEP), which had the experience and knowledge to develop mixed energy systems. ACEP agreed and met with the Tribal Council of Igiugig, where it was decided that they would collaborate on this part of the project. In July 2019 it was widely reported in Alaska that the village of Igiugig was the first tribal entity in the nation to be licensed by the Federal Energy Regulatory Commission to use an innovative underwater twin-turbine generator. The testing of this innovation provided solid evidence that the salmon run was not affected by the technology. No salmon were killed. The Alaska State governor, an Alaska senator, ACEP, the Village Council, and many others were there to celebrate the application and success of this innovation. 
"We would like clean renewable energy over diesel any day," said Igiugig tribal council President AlexAnna Salmon. "We are a very environmentally focused community and that is in alignment with our cultural values, which is to leave as little footprint as possible on this earth" (Anchorage AP, 2019, https://apnews.com/article/9014bfaf806d4bb69199505b00e0e44a). This highly complex collaboration included the Village Council, the Alaska Native Science Commission, private enterprise with an energy renewable firm, multiple layers of government, and a transdisciplinary effort by UAF. As part of this collaboration the village wanted to develop a cultural program with an emphasis on Yup'ik language revitalization, as the only speakers in the village were a few Elders. They developed a plan that included a community-oriented and school-based program. To meet this goal the village council hired Evelyn Yanez. Evelyn had lived in the village for long periods of time and had worked with the few remaining Yup'ik speakers, collecting, transcribing, translating, and producing Yup'ik stories. She worked with a local artist to illustrate the stories. She provided spoken Yup'ik language instruction to the village and school. Evelyn Yanez ${ }^{13}$ (phone call October 13, 2020) says that her work continues, and AlexAnna Salmon (phone call October, 2020) said that she has over ten concurrent grantfunded projects. Quite an accomplishment for a community of 69 people!

\subsection{Federated States of Micronesia (FSM) and Republic of the Marshall Islands (RMI)}

\subsubsection{Introduction}

I was introduced to Yap State (FSM) and the Marshall Islands (RMI), located in the western and central Pacific Ocean, through an ethnomathematics-oriented grant, when Sandy Dawson, who was the Principal Investigator, invited me to join the project.

The following vignettes express the deep emotional, cultural, and psychological struggles of Indigenous People of Yap State and the Marshall Islands in adapting to socio-political, and economic changes affecting their Pacific Island nations. The vignettes attempt to reflect the existential crises engendered by environmental and political injustices, and the importance of a cultural and community identity deeply tied to intimate knowledge of the sea and to island atolls. Each vignette highlights central aspects of outer islanders' cultural traditions, which developed from their long-standing ecological and culturally sustainable ways of living with the sea and on

\footnotetext{
${ }^{13}$ Evelyn Yanez is a long-term colleague. We began working together in 1981 when she was a student in the teacher education program, earning her teaching degree, and continued collaborating until 2017.
} 
low-lying islands. Canoes embody fundamental aspects of their respective cultures: canoe house construction, canoe building, and navigation. In response to events that are leading to existential threats so similar to Alaska's Indigenous People and to the question, "does one way of life have to die so another can live" (Yupitak Bista, 1974), these vignettes are a witness to drama, tenacity, and herculean efforts by Indigenous People to find a way to navigate the turbulent patterns of modernization (generously stated) by drawing on traditional knowledge and practices.

To counter these threats, Larry Raigetal established Waa'gey, an NGO community-based program in Yap State. Larry Raigetal saw the need to deliberately pass on cultural knowledge related to canoe navigation and other aspects of his culture. He expresses the essence of Waa'gey as "looking back to know where you are going," a phrase that captures a navigational technique used at the beginning of a long-distance canoe trip.

Alson Kelen is the director of Waan Aelõñ in Majel (WAM), which translates to "Canoes of the Marshall Islands." WAM was developed to revive canoe building and navigation. WAM is located on Majuro, the capital of the Marshall Islands. Alson Kelen's vision, malene ilju pādpād ion inne (shape the future based on the past) (Genz, 2018, location 4297 Kindle Edition) is similar to the vision of Larry Raigetal. These two leaders view the canoe as the embodiment of their respective cultures. "A core understanding of $w a$ [canoe] thus rests on the idea of people metaphorically sailing through life on particular courses" (Carucci, 1995, p. 21). One part of the canoe supports all the other parts (Genz, 2018, location 1190 Kindle Edition). In this regard, "canoe" and "navigation" are viewed symbolically as connecting the past to the future and are foundational to outer islanders in Yap State and Marshallese cultures.

\subsubsection{Brief Overview}

The FSM and the RMI are located in the western and central Pacific Ocean, and consist of high and low-lying islands, islets, atolls, and coral reefs in a huge expanse of water (Carucci \& Poyer, 2017, p. 207). Different cultural and linguistic groups traveled to and settled these island nations. For example, Yap State basically comprises two linguistic and cultural groups: the Yapese people reside on the main Yap Islands (a complex of four connected islands), several related dialects that form part of what linguists refer to as "the Trukic continuum." Collectively, the people living in this region are referred to as Micronesians. The focus of people living among the low-lying atolls is the sea. These islanders are well known for their navigating skills. In addition 
to being master navigators, Micronesians are canoe builders, fishers, and horticulturists. High island people such as the Yapese have a much larger land base with multiple ecological niches; they rely more heavily on farming, cultivating plants, raising animals, and making use of the sea's bounty. This simple overview generally holds throughout Micronesia (Feinberg, 1995).

In the modern era, this region has been colonized by England, Spain, Germany, Japan, and the U.S. Each successive wave of colonizers impacted the local cultural group and its practices. Japan administered Micronesia as a Class C Mandate under the League of Nations prior to World War II, and after World War II, Micronesia became a Trust Territory of the Pacific Islands (TTPI) under the auspices of the United Nations. The FSM and the Marshalls became independent in 1986, and Palau followed in 1994. These island nations' relationship with the U.S. is defined by Compacts of Free Association (COFA), which are tailored and timed differently for the three island nations. These agreements obligate the U.S. to provide financial and other forms of assistance for a set number of years, and take full responsibility for defense. Citizens of the COFA nations also benefit from being able to relocate to the U.S. and its territories, and many have moved to Guam, Hawai' $i$, and the U.S. mainland. The Compact of Free Association has proved critical for the Micronesian nations.

The two community-based organization vignettes that follow shed light on multiple ways of adapting to changing cultural and ecological conditions through the development of new alliances.

\subsection{Case Vignette: Waa'gey (an NGO in Yap State)—Cultural Survival, Revival, and Adaptations to a Rapidly Changing World}

To the east of the main Yap Islands is a low-lying chain of coral islands closer in language and culture to Chuuk. These islands were home to traditional voyaging schools. Such schools as the one in Satawal were instrumental in reviving traditional canoe navigation in Polynesia under the leadership of Mau Piailug, a master navigator. Larry Raigetal grew up on neighboring Lamotrek, a small atoll. People from these atolls are commonly referred to as Rei-metau, which means "people of the ocean." In fact, Larry Raigetal's cousin, Ali Haleyalur, is considered a grand master navigator, and he is an important part of Waa'gey.

Because of rising sea levels, the ecology of these islands is dramatically threatened by saltwater intrusion into the islands' aquifers, and more frequent storm washover events. The plant and tree 
ecology of the area, which once consisted of sufficient stands of pandanus, coconut, taro, and other species, now is threatened by rising brackish waters. These plants were used for weaving, canoe carving, foods, and beverages. In a way, they were the perfect ecologically sustainable natural resource, having multiple uses with minimal impacts (for a more detailed account see Carucci \& Poyer, 2017, p. 210). Increased imports of non-biodegradable products also impact the lagoons and lands. With the subsistence economy increasingly under threat and the need for cash and employment becoming more critical within the population, outmigration has become the choice of many.

\subsubsection{Coming Home-Embracing Traditions and Modernity}

As a young man, Larry Raigetal recounts that when he visited Yap Main Island, there were few outer islanders living there. Today, the number of outer islanders living on Yap Main Island has increased dramatically. The pressures exerted by climate change, economic opportunity, and a desire for new cultural experiences are draining the outer islands of their populations. Larry Raigetal was one of those who sought to leave his home in Lamotrek Atoll, and below he describes his journey.

When I was twelve or thirteen, I found myself in California. Eventually getting my undergraduate study and then to England to get my graduate study. I returned back [home] to the government in the Federated States of Micronesia. I worked as a diplomat for some years and then returned to work with that government for some years. Eventually, I found myself in the jungles of Yap working, carving canoes, and teaching young people traditional skills. So, I kind of think to myself that ... not too sure what I'm doing. But the only one sure thing I know is that of all these years that I've gone to get my degrees I found out that I know very little and I'm still learning. [excerpt from https://www.youtube.com/watch? $\mathrm{v}=\mathrm{SCsq} 6 \mathrm{cEzHpM} \& \mathrm{t}=1842 \mathrm{~s}$ at the Micronesian Area Research Center, talk by Larry Raigetal]

The experience of living away increased Larry's appreciation of his cultural traditions, community cohesiveness, and the knowledge associated with living on outer islands.

Waa'gey is not only the name of a community-based organization, but also is a word that describes a cultural way of being for the Indigenous People of these islands. They believe that their ancestors developed the most suitable and sustainable ways of successfully living in this island and ocean environment. Larry Raigetal believes that the ancestors of his people were geniuses, as they developed the skills, knowledge, and technologies that allowed them to live so well. 
Theirs was a true stewardship system designed to sustain future generations by caring for mother earth. Waa'gey is dedicated to keeping traditional practices alive, including skills of seafaring, weaving, handicraft making, and sustainable methods of using resources such as local fish traps by engaging our elders, who can pass these vital skills on to the younger generation, especially as climate change forces islanders to relocate, altering social structures and these traditional practices. [Raigetal, https://ichcourier.unesco-ichcap.org/article/climatechange-and-its-impact-on-the-culture-of-the-remote-outer-islands/]

The Yupiaq Indigenous practitioner/scholar research group visited Yap Main Island in $2015^{14}$ and had the opportunity to work with Larry Raigetal and Ali Haleyalur, master navigator, and Cal Hachibmai, Yap State Department of Education. The two groups shared knowledge regarding traditional ways of measuring, creating tools using a halving process and symmetry, house construction, and navigation. These meetings took place as Waa'gey and Larry Raigetal and Ali Haleyalur were preparing for the $12^{\text {th }}$ Festival of Pacific Arts (FesPac), which was held in 2016 in Guam. Figure 3 is the Simion Hokulea traditional canoe built by master carver and navigator Mau Piailug from Satawal who was instrumental in canoe revival in Hawai'i).

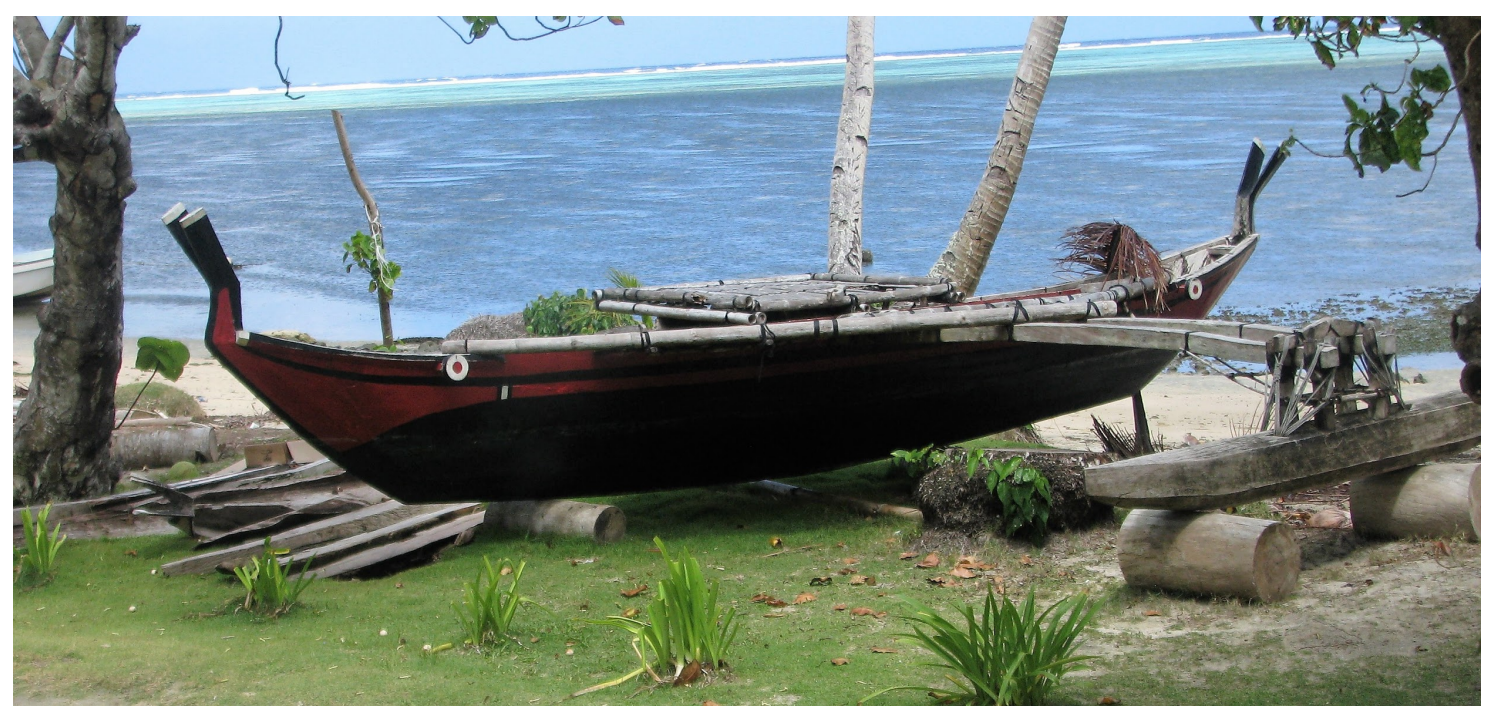

Figure 3: Traditional voyaging canoe with an outrigger

Source: Jerry Lipka

The festival was instituted to combat erosion of traditional knowledge and practices. Participants came from 27 Pacific Island nations and territories. Larry Raigetal stressed the importance of refurbishing the canoe house, as the canoe house cares for the canoe. Ali Haleyalur was involved in preparing a new generation of navigators. This preparation culminated when, for the first time in years, Waa'gey held a sacred initiation, $p w o$, which recognizes the technical and spiritual learning of the apprentice navigators.

\footnotetext{
${ }^{14}$ During the course of our grants, our research group met approximately six times with our partners from Yap.
} 
A small fleet of traditional voyaging canoes was readied for travel in conjunction with the ceremony. The voyaging canoes would sail from Lamotrek and other neighboring islands for four or five days until they reached Guam and the festival. An intrinsic act of reviving part of the canoe tradition, the community of Lamotrek decided to weave a traditional pandanus sail. The essence of Waa'gey is bringing together Elders and youth, some as young as five years old. The pwo ceremony involves the community in song, dance, rituals, prayers, and the construction of canoes and sails. During the $p w o$ ceremony, canoes were launched and two new master carvers were initiated. The following excerpt comes from a video of Waa'gey's preparations for the festival in Guam.

Part of Waa'gey's traditional cultural knowledge was to have the community of Lamotrek weave a traditional voyaging sail made from pandanus leaves. This is an ambitious project and had not been done for years. It involves the entire community. Women harvest the leaves, dry and split, and weave them into a special mat. The men stitch together the mats with rope that makes them into a sail. Yet at the start of the project there was a big problem. No one seemed to know the entire process. They realized at the very last moment that Maria, an elderly very sick woman, had this knowledge. Once she taught the women how to weave the pandanus leaves, it took 50 women working full-time for two-weeks to weave the sail. [The narrator continues speaking in the present tense as the actions and ceremonies unfold.] With the ability to weave the sail the community wove a message about climate change into the sail. Larry Raigetal hoped the woven message in the sail will raise awareness at FesPac and beyond. Before the sailing the community held a departure ceremony. Ali will be the captain of the largest canoe and then sanctioned to be the lead for the voyaging canoe. He needs to be purified. After that, through sanctifying ceremonies, final blessings, and empowerment, Ali purifies the group and cuts away the fears and doubts and insecurities that the boys (crews) may have. After the final blowing of the conch the ceremony was concluded, and the voyage begins. [excerpt from Waa'gey, a video located at https://www.youtube.com/watch?v=tZGZP2fR6ic]

The voyage to Guam was not without incident. Stormy weather presented a new obstacle as one Lamotrek canoe broke its mast and another began taking on water, and one had to be rescued by the US Coast Guard and towed to Guam. As they neared Guam, the voyaging canoes sailed into the harbor under their own power and they were warmly greeted by festival participants. At the opening ceremonies of the Festival of Pacific Arts, Larry Raigetal discussed the fragility of cultural and ecological systems. This fragility was manifested with the death of Maria, who passed on her knowledge to the women of Lamotrek. Larry Raigetal expressed his deep concern about climate change effects on the outer islands, the future disruption of the People's way of life that would follow such effects, and the uncertainty that all this was causing the community. 


\subsection{Case Vignette: Marshall Islands and WAM-Resilience, Island Survival, and the Canoe}

\subsubsection{Introduction}

This case vignette is introduced by the activism of Kathy Jetnil-Kijiner, a Marshallese poet, performance artist, and educator. An inspiring individual who is working with the youth on Majuro, Marshall Islands, Kathy was selected from 500 candidates to speak at the United Nations Climate Summit in New York in 2014 (https://www.youtube.com/watch?v=L4fdxXo4tnY).

At the Summit, Kathy read her poem to the attendees, an emphatic promise to her infant (paraphrased) that no one will take away your land, your home, or your heritage. Kathy is deeply rooted in these specks of land that were once a large Pacific volcano atop an ocean tectonic plate that slowly shifted westward and subsided over the eons and became tiny vulnerable atolls. The Marshall atolls were home to some of the finest carved canoes in the Pacific. Exceptional craftsmanship was coupled with the extraordinary skills of wave pilots - master navigators. This case vignette briefly explores the unimaginable - that the canoe and wave finding (the traditional skill of sensing subtle wave patterns) may literally and figuratively be able to navigate these treacherously rising waters by reinvigorating cultural pride embodied in the canoe, using advanced canoe technology to reduce the carbon footprint, and open economic possibilities.

\subsubsection{The Fallout from the U.S. "Protectorship"}

After World War II, the United Nations (UN) was authorized to protect and promote the welfare of the Marshallese people and inhabitants of other parts of the central and western Pacific. The U.N. granted authority to the U.S. to administer the special strategic Trust Territory of the Pacific Islands (TTPI). Under this agreement, the U.S. promise to protect this region was clearly antithetical to its military goals. The U.S. viewed this chain of islands as strategically important in geopolitical and military terms. With established defense installations on Kwajalein and Enewetak, the U.S. chose nearby Bikini Atoll as its initial atomic test site. Beginning in 1946 (ending in 1958) with the Able test, 67 nuclear tests took place in the Marshall Islands. Unfortunately, the fallout from this human tragedy is still being experienced by the Marshallese. The details are gruesome: from genetic distortions and deformity, forced relocations, and cultural and psychological shock, to the disruption of traditional navigation schools. Kwajalein continues 
as a missile test site, staffed mainly by civilian contractors, and Enewetak continues as a nuclear waste storage site. Despite this, resilience remains.

\subsubsection{The Slow and Steady Revival of the Canoe and Sustainability-Captain Korent Joel, Alson Kelen, and Joe Genz}

Korent Joel's traditional wave finding training was disrupted by the thermonuclear test of 1954 at Rongelap Atoll, which resulted in radioactive fallout that impacted the Rongelapese community. As a young boy, Korent Joel was originally taught by his grandfather, who had him lie down inside of a small boat within the atoll's protected waters. He was instructed to sense/feel/orient himself to the incoming wave patterns.

Years later, experience at sea earned Korent Joel the title of Captain, a term drawn from the English language, with the Marshallese meaning of "navigator." His time on government transport ships and rescue vessels allowed him to continue to learn and experiment with his traditional knowledge, which he always wanted to confirm and expand on. This interest led to a collaboration with Joe Genz (anthropologist at the University of Hawai'i at Hilo) and Captain Korent Joel's relative Alson Kelen, who was also involved in the canoe revival movement. Korent Joel, Alson Kelen, and Joe Genz sought assistance from the few remaining master navigators. Korent Joel's training, which had been prematurely stopped as a result of the nuclear testing, resumed in the early 2000s when he re-learned some aspects of wave piloting from a small group of navigators, most of whom were from Rongelap. The cultural protocols of taking a voyage at sea to demonstrate one's navigational prowess were still in place, though they had not been enacted in nearly half a century. At the beginning of the revival project, Captain Korent Joel had not yet been sanctioned as a master navigator. He received permission from his chief to continue his learning and later take his navigational test at sea. During this time, Alson Kelen, his apprentice, would document Captain Korent Joel's knowledge, but any formal training (for Alson) had to wait until Captain Korent Joel became sanctioned by the chief as a navigator, which happened in 2006 during a voyage between the atolls of Kwajalein and Ujae. Captain Korent Joel could then train Alson Kelen in this skill because they were related (personal communication with Joe Genz). 


\subsubsection{The Next Wave Finding Test—Verifying the Dilep}

Greatly simplified, wave finding is the art and science of traditional Marshallese navigating, which includes the skill of sensing subtle wave patterns. Due to the complexity of trying to describe what wave finding entails, the focus here will be on only one of its aspects. As waves impact atolls or islands, they cause reflections, refractions, and diffractions (Ascher, 1995). Teaming up with Joe Genz and Alson Kelen, Captain Korent Joel was interested in working with scientists using data and computer modeling to better understand his tradition and to have his knowledge verified. Captain Korent Joel clearly made his desire known to Joe Genz that scientists should be involved in witnessing this practice. The two systems - one based on keen observations, proprioception, and advanced intuitive knowledge, and the other grounded in oceanography, physics, and computer modeling — could complement each other.

One wave pattern that Captain Korent Joel learned to sense is called dilep in Marshallese and backbone in English. Dilep connects two atolls arising from complex subtle wave interactions. The invited scientists John Huth, a particle physicist at Harvard University, and Gerbrant van Vledder, a wave modeler from Delft University in the Netherlands, traveled to Majuro in RMI to identify this wave pattern.

As so much of this story is filled with tragedy and courage, this episode is no different. Right before the sailing, Captain Korent Joel became severely ill. He still deeply believed in this collaboration with the scientists. Visiting Captain Korent Joel in his home in 2015, the scientists shared with him their preliminary wave modeling results. The intent had been for Captain Korent Joel to share his ideas and then demonstrate his skills at sea. This critical component of knowledge exchange was not possible due to his illness. The project would have ended there except that Alson Kelen, still an apprentice, volunteered to guide the canoe between the two closely spaced atolls of Majuro and Aur.

Students from the Waan Aelõñ in Majel (WAM) program assisted in multiple ways to ready the sailing canoe. Alson Kelen would now be accompanied by Joe Genz and the scientists who voyaged in another boat as a safety backup and to collect additional data.

Alson Kelen successfully navigated this open ocean trip, atoll to atoll and return. Though the trip had its travails, the scientists collected data and mapped waves generated by the north winds and waves generated from the four corners of the earth. Gentle swell waves move thousands of 
kilometers across the Pacific from the north and the south. They meet in the central Pacific near the Marshall Islands and mix with local waves. Alson Kelen, like his seafaring ancestors, could wave find and pilot the canoe based on subtle yet reliable patterns. The dilep wave pattern felt by Captain Joel Korent and Alson Kelen remained elusive for the scientific team. As of this writing, according to Gerbrant van Vledder, "Although we use computer models, I realize that our knowledge is still incomplete, ... But we are still not there. All the computer models are simplifications. And I expect that we can still learn a lot from what the navigators know .... what do they feel?" (Excerpted from Harvard University's Ratcliffe lecture series hosted by John Huth (physicist) and panelists Joe Genz, Alson Kelen, and Gerbrant van Vledder (oceanographer who specialized in wave dynamics, July 2017 https://www.youtube.com/watch?v=voy8Dd4bqIg)

Alson Kelen's training remains incomplete. He is not a titled navigator. He has extensive experience and is now the key person that the maritime community turns to for questions about canoes and navigation, but his journey toward becoming a sanctioned navigator remains uncertain, as the traditional means of sanctioning have been disrupted. The Marshallese culture is in transition, and as Alson Kelen apprentices new wave finders, it makes the once secret and sacred knowledge of wave finding public; it alters the chiefs' authority and power, as they were the keepers of this knowledge. This is the dilemma the canoe revival movement faces as it navigates a changing culture. [See Joe Genz (2018) in-depth description of the revival movement, and Waan Aelõñ in Majel (WAM) (https://www.canoesmarshallislands.com/) provides a history of the revival movement.]

\subsubsection{From Canoe and Wave Finding to Climate Action}

This cultural reawakening has received strong support from multiple organizations, from WAM, major donors, international organizations, and from Hilda Heine, first female president of the Marshall Islands (2016-2020). The Marshallese government realized that the price of fuel, which is expensive, and their reliance on shipping were contributing to greenhouse gas emissions, and it took action to reduce the islands' own emissions. This choice resulted in a complex initiative between the RMI and the University of the Pacific and its Micronesian Sustainable Transport Center. The German Ministry of Environment and an innovative German company are also major partners in this effort. The goal is to develop and use inter-island canoes based on 
traditional canoe-building practices but adapted in size and scale to be a functioning longdistance and inter-island transport system. These prototype vessels are being tested now.

\section{Discussion-Changing Paradigms and Navigating Existential Threats and Climate Change}

My previous focus on existential cultural threats to small Indigenous groups has shifted to a social-ecological-cultural systems perspective. This perspective switches from micro-aggressions occurring at the intersection of school and community to fundamentally supporting and strengthening Indigenous resilience and adaptation. The social-cultural-ecological paradigm recenters the community and its organizations and decenters the school. This theoretical change alters the power dynamic between school and community. The discussion of the vignettes highlights a multiplicity of opportunities and challenges that remain.

\subsection{The Importance of Indigenous Practitioner/Scholar Groups}

Indigenous practitioner/scholar groups assisted by invited academics are a powerful building block in supporting, documenting, and revitalizing TEK, as described in four of the vignettes. Three cases revolved around cultural knowledge on the edge of extinction, such as the last star navigator, wave finders, and traditional pandanus weavers, and there are many similar untold stories. Group synergy and TEK itself tap into human curiosity and multiple epistemologies and worldviews. These efforts and collaborations have a propensity to attract interested others and establish multiple linkages in a community or region, potentially connecting and strengthening cultural knowledge.

Three of the vignettes highlighted collaborations desired by Indigenous Elders or groups, especially the Marshallese vignette. Captain Korent Joel vividly portrayed differences in epistemologies and ways of verifying knowledge. His understanding of multiple sensory inputs, his memorized knowledge of routes and sea markers, and his ability to process this information in real time (Genz, 2014) represent a prime example of differences in Indigenous and western epistemologies. Captain Korent Joel wished for a way to validate his method and wanted to understand complementary ways of thinking. Joe Genz and Alson Kelen continue the pursuit of finding scientific validation, which remains elusive. Nonetheless, the search for understanding wave finding has brought external attention to this ancient art, providing insights on ways to 
revitalize these practices and increase humanity's understanding of cognition and embodiment. More important to the Marshallese are the deep cultural ties to traditional canoe building, and navigating by wave finding, which are directly linked to climate change concerns through adaptive and symbolically powerful cultural practices and knowledge.

Though a small sample, the vignettes described here are qualitative evidence of how science and economic opportunity play an important role in the potential for ecological sustainability. Three vignettes-Igiugig, the Alaska Gateway School District, and the Marshall Islands-illustrate how green technologies that involve insiders and outsiders working together can combine economic development and sustainable growth while supporting Indigenous autonomy.

\subsection{Waa'gey - Building on Cultural Traditions When Ecological Systems Change}

Waa'gey, composed of outer islanders, continues to look for possible partnerships and technologies that expand upon the use of their traditional canoe, a possible means of low-cost and environmentally clean inter-island transport which is currently lacking. Presently, the one Chinese-built vessel that islanders rely on for transporting goods and critical supplies sits broken in Colonia, the capital of Yap State (personal communication with Cal Hachibmai). Solutions to the ecological, economic, and transport systems remain tenuous as a potential collaborative project concerning sea transport was not economically feasible (personal communication with Larry Raigetal).

Part of Waa'gey's program includes being simultaneously culturally traditional, adaptive, and creative under conditions of large-scale environmental changes. The ancient art of navigating in some ways begins with learning the procession of rising and setting stars. In Figure 4 below Ali Haleyalur demonstrated the set of rising/setting stars used in navigating. However, Larry Raigetal explained the star map also functions like a calendar, indicating times of stormy and calm weather. Climate changes has altered these patterns, presenting new challenges to the art and science of navigating. 


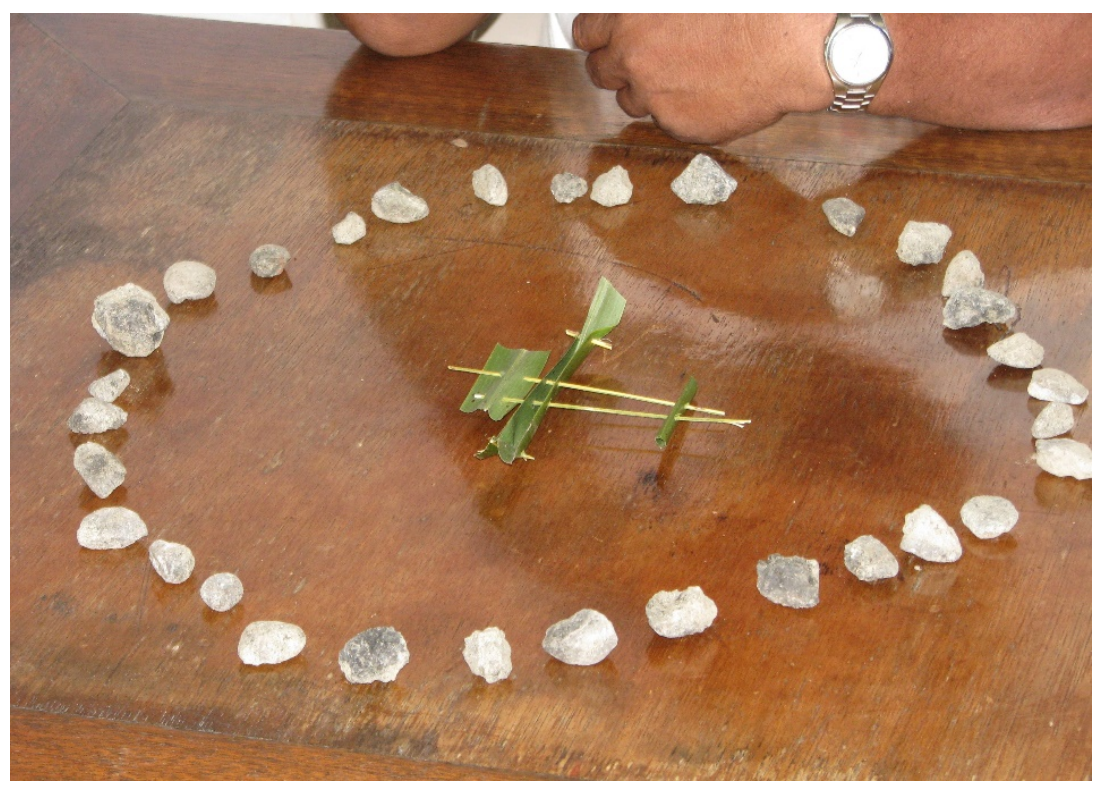

Figure 4: Tradition tool for teaching and memorizing star progression

Source: Jerry Lipka

I believe that the Marshall Islands and Waa'gey vignettes encapsulate the urgency for action in the face of climate change effects that are undermining the ability to live on these atolls and islands. The Marshall Islands are already losing land through coastal erosion, and the outer islands of Yap face mounting existential threats to rapidly changing environmental conditions. The Islanders need economic opportunity, which they are already partially linking to traditional culture and knowledge. They are at the epicenter of climate and social-cultural-ecological change.

\subsection{Building on Local Indigenous Groups and Developing Multiple Systemic Linkages}

The Republic of the Marshall Islands (RMI) has developed multiple systemic linkages within its society and to regional and international organizations. The many connections of Waan Aelõñ in Majel (WAM) that initially stemmed from cultural pride and revitalization of wave finding, canoe building, and workforce education for youth have opened up new spaces for opportunity. These opportunities are bolstered by the credible steps that the RMI government has made in establishing working relationships with the U.N., Japan, Taiwan, and Germany regarding funding and technological assistance. The RMI and WAM are working with the University of the South Pacific on designing and developing Low Carbon Sea Transport (canoe/boats), and at the present time are field testing the adapted canoes and boats inside lagoons. WAM and the 
Marshall Islands Shipping Corporation have a role in building the boats, offering employment opportunities and training youth, with promising possibilities of work following graduation. The RMI is working with Indigenous Knowledge holders, scientists, land planners, and many others using satellite imagery to study rising waters and the dynamics of the atolls as islanders face the consequences of a 2.0 degree centigrade rise in temperature. This collaboration includes a plan to elevate some of the atolls above predicted sea level estimates. The goal of this collaboration means modifying a habitat purposely for ecological, environmental, economic, and subsistence sustainability, guarding against salinization of the freshwater supply and introducing alternative solar-powered energy sources. Such collaborations also mean the survival of the traditional canoe.

\subsection{Ethnomathematics--where is it?}

Ethnomathematics is embedded throughout this article. By supporting community organizations such as Waa'gey and WAM, Indigenous epistemologies may strengthen, sustain, and generate new pathways of knowledge and living. Traditional Ecological Knowledge applied to fire suppression, forest stewardship and climate change can be part of a solution to the challenge of sustaining or promoting economic well-being (Huaman, $2016 \& 2020$ ). This broad array of possibilities opens creative paths for the application of ethnomathematics developing regenerative social, cultural, economic, and educational systems that attempt to redefine how to live harmoniously with the natural environment in the modern era.

\section{IN CONCLUSION}

Indigenous People in the places described contribute a tiny, tiny fraction of worldwide climate emissions. The Marshall Islands government and people have resolved to further lower their carbon emissions so that their local actions reflect and reinforce the changes they are asking of the rest of the world. It seems only just that ethnomathematicians and ethnographers and other social scientists respond to Laura Nader's (1974) suggestion to "study up." Facing the damaging effects of climate change leads to questions such as these: What can influence decision makers to recognize the costs that are irresponsibly passed on to others? How can stockholders, banks, and governmental policymakers act responsibly toward our planet? To paraphrase Nader, her challenge to all of us is, work in the halls of power, business, and government, to study their 
culture and influence their decision making for the benefit of the commons. Without these types of efforts, small Indigenous communities and cultures will be hard-pressed to stop the macro forces encroaching on their existence. This should be a warning and call to action for all of us.

\section{ENDNOTES}

[1] See Lipka, J. with Mohatt, G., \& the Ciulistet Group. (1998). Transforming the Culture of Schools: Yup'ik Eskimo Examples. Because much of this topic has been addressed, this paper raises processes and topics not well covered or not addressed in previous work.

[2] Ray Barnhardt is recognized here for creating the space within the University of Alaska Fairbanks to establish Indigenous teacher training programs, an Indigenous doctoral program, and for his support of systemic change throughout the state. Gerald Mohatt, a dear friend and Dean of the Rural College, spread this approach to other academic programs within the college and established the Center for Alaska Native Health Research and multiple programs under this center. These efforts created space for new programs and access to higher education for Indigenous Alaskans which continue.

[3] Esther Ilutsik was a leader in establishing the Teacher and Elder group.

[4] We developed ethnomathematics supplemental curriculum and storybooks (traditional and modern), which we called modules.

\section{REFERENCES}

Adams, B., Kagle, M., \& George, F. (2007). Star Navigation: Explorations into Angles and Measurement. [Publication out of print, but available at https://www.uaf.edu/mcc/mcc_resources/modules.php]

Ascher, M. (1995). Models and maps from the Marshall Islands: A case in ethnomathematics. Historia Mathematica, 22(4), 347-370. https://doi.org/10.1006/hmat.1995.1030

Barajas-López, F., \& Bang, M. (2018). Indigenous making and sharing: Claywork in an Indigenous STEAM program. Equity \& Excellence in Education, 51(1), 7-20. https://doi.org/10.1080/10665684.2018.1437847

Carucci, L. M. (1995). Symbolic imagery of Enewetak sailing canoes. In R. Feinberg (Ed.), Seafaring in the Contemporary Pacific Islands: Studies in Continuity and Change (pp. 16-33). DeKalb: Northern Illinois University Press.

Carucci, L. M., \& Poyer, L. (2017). The West Central Pacific. In A. Strathern, P. J. Stewart, L. M. Carucci, L. Poyer, R. Feinberg, \& C. Macpherson (Eds.), Oceania: An introduction to the cultures and identities of Pacific Islanders. (pp. 183-250).

Chapin, F. S. (2020). Grassroots stewardship. Oxford University Press. 
Chapin, F. S., Trainor, S. F., Huntington, O., Lovecraft, A. L., Zavaleta, E., Natcher, D. C., McGuire, D, Nelson, J. L., Ray, L., Calef, M., Fresco, N., Huntington, H., Rupp, T. S., DeWilde, L., Naylor, R. L., \& Fresco, N. (2008). Increasing wildfire in Alaska's boreal forest: Pathways to potential solutions of a wicked problem. BioScience, 58(6), 531-540.

Chapin, F. S., Knapp, C. N., Brinkman, T. J., Bronen, R., \& Cochran, P. (2016). Communityempowered adaptation for self-reliance. Current Opinion in Environmental Sustainability, 19, 67-75. https://doi.org/10.1016/j.cosust.2015.12.008

Cochran, P., Huntington, O. H., Pungowiyi, C., Tom, S., Chapin, F. S., Huntington, H. P., \& Trainor, S. F. (2013). Indigenous frameworks for observing and responding to climate change in Alaska. In Climate Change and Indigenous Peoples in the United States (pp. 49-59). Springer, Cham.

Cole, M. (1998). Cultural psychology: A once and future discipline. Harvard University Press.

Cole, M., \& Engeström, Y. (1993). A cultural-historical approach to distributed cognition. In Distributed Cognitions: Psychological and Educational Considerations (pp. 1-46).

Davis, W. (2003). Dreams from endangered cultures. Ted talks https://www.ted.com/talks/wade davis dreams from endangered cultures

Engblom-Bradley, C. (2006). Learning the Yup'ik way of navigation: Studying time, position, and direction. Journal of Mathematics and Culture, 1(1), 90-126.

Feinberg, R. (1995) Modern Pacific seafaring. Dekalb, Illinois: Northern Illinois University Press.

Genz, J. (2014). Complementarity of cognitive and experiential ways of knowing the ocean in Marshallese navigation. Ethos, 42(3), 332-351.

Genz, J. (2018). Breaking the shell: Voyaging from nuclear refugees to people of the sea in the Marshall Islands. Honolulu: University of Hawai'i Press, Kindle Edition.

Hardin, G. (1968). The tragedy of the commons. Science, 162(3859), 1243-1248. https://doi.org/10.1126/science.162.3859.1243

Huaman, E. S. (2016). Tuki Ayllpanchik (our beautiful land): Indigenous ecology and farming in the Peruvian highlands. Cultural Studies of Science Education, 9(3), 1135-1153.

Huaman, E. S. (2020). Small Indigenous Schools: Indigenous Resurgence in Education in the Americas. Anthropology \& Education Quarterly, 51(3), 262-281.

IPBES. (2019). Summary for policymakers of the global assessment report on biodiversity and ecosystem services of the Intergovernmental Science-Policy Platform on Biodiversity and Ecosystem Services. S. Díaz, J. Settele, E. S. Brondízio, H. T. Ngo, M. Guèze, J. Agard, A. Arneth, P. Balvanera, K. A. Brauman, S. H. M. Butchart, K. M. A. Chan, L. A. Garibaldi, K. Ichii, J. Liu, S. M. Subramanian, G. F. Midgley, P. Miloslavich, Z. Molnár, D. Obura, A. Pfaff, S. Polasky, A. Purvis, J. Razzaque, B. Reyers, R. R. Chowdhury, Y. J. Shin, I. J. Visseren-Hamakers, K. J. Willis, \& C. N. Zayas (Eds.). IPBES secretariat, Bonn, Germany. 56 pages. https://doi.org/10.5281/zenodo.3553579

Jacobson, S. A. (1984). Semantics and morphology of demonstratives in Central Yup'ik. Etudes/Inuit, 8, 185-192. 
Kawagley, A. O. (2006). A Yupiaq worldview: A pathway to ecology and spirit. Waveland Press.

Lipka, J. (1990). Integrating cultural form and content in one Yup'ik Eskimo classroom: A case study. Canadian Journal of Native Education, 17(2), 18-32.

Lipka, J. (1991). Toward a culturally based pedagogy: A case study of one Yup'ik Eskimo teacher. Anthropology \& Education Quarterly, 22(3), 203-223.

Lipka, J., \& Willer C. (1985). Planning, Development, and Change in Bristol Bay: A High School Curriculum. Teacher Guide and Student Text. Unit I: Introduction. Unit II: Village Corporations. Revised. ERIC.

Lipka, J., with Mohatt, G., \& the Ciulistet Group. (1998). Transforming the culture of schools: Yup'ik Eskimo examples. Mahwah, NJ: Lawrence Erlbaum.

Lipka, J., Adams, B., Wong, M., Koester, D., \& Francois, K. (2019). Symmetry and measuring: Ways to teach the foundations of mathematics inspired by Yupiaq Elders. Journal of Humanistic Mathematics, 9(1), 107-157.

Nader, L. (1974). Up the anthropologist—Perspectives gained from studying up. In D. Hymes (Ed.), Reinventing anthropology (pp. 284-311). New York: Vintage Books.

O’Neill, D. (1994). Firecracker boys: H-Bombs, Inupiat Eskimos, and the roots of the environmental movement. St. Martins.

Tamura, Y. (2017). A Supplementary Description of the Use of Demonstratives in Central Alaskan Yup'ik. 言語文化共同研究プロジェクト, 2016, 31-40.

Veit, P., \& Reytar, K. (2017). By the numbers: Indigenous and community land rights. World Resources Institute. March 20. https://www.wri.org/blog/2017/03/numbers-indigenousand-community-land-rights.

Wackernagel, M., \& Beyers, B. (2019). Ecological footprint: Managing our biocapacity budget. New Society Publishers.

Yupiktak. Bista. (1974). Does One Way of Life Have to Die So That Another Can Live? A Report on Subsistence and the Conservation of the Yup'ik Lifestyle. A. Davidson (Ed.). Yupiktak Bista, Bethel, AK. 